\title{
Laser Ablation Surgery in Late Stage Buccal Cancer
}

\author{
Rusy Bhalla, Seemantini Bhalla, Duleep Bhonsale, Dilip Pawar* \\ Orchid Cancer Centre for Laser Surgery, Mumbai, India
}

Received August 28, 2020; Revised November 11, 2020; Accepted November 29, 2020

\begin{abstract}
Cite This Paper in the following Citation Styles
(a): [1] Rusy Bhalla, Seemantini Bhalla, Duleep Bhonsale, Dilip Pawar, "Laser Ablation Surgery in Late Stage Buccal Cancer," Cancer and Oncology Research, Vol. 6, No. 3, pp. 47 - 52, 2020. DOI: 10.13189/cor.2020.060301.

(b): Rusy Bhalla, Seemantini Bhalla, Duleep Bhonsale, Dilip Pawar (2020). Laser Ablation Surgery in Late Stage Buccal Cancer. Cancer and Oncology Research, 6(3), 47 - 52. DOI: 10.13189/cor.2020.060301.
\end{abstract}

Copyright $\odot 2020$ by authors, all rights reserved. Authors agree that this article remains permanently open access under the terms of the Creative Commons Attribution License 4.0 International License

\begin{abstract}
Oral cancer is a major health problem in India. The use of tobacco in various forms has escalated the problem to be the leading cause of cancer in males in India. Many patients postpone surgery for fear of facial mutilation and therefore present with Late stage Buccal Cancer. The management of Late stage buccal cancer has very few options. Conventional surgery, chemotherapy and radiation give very little relief to patients. The occurrence of inevitable recurrence after surgery due to Field cancerisation makes the surgery a futile exercise in controlling the spread of the tumor. The treatment in unresectable tumors which is given as palliation is often limited to pain control and bypassing of oral functions by inserting a nasogastric tube. The mortality rate has remained changed over last 10 years. Therefore Quality of life in these patients has become a discussion matter in most cancer forums. The main cause of the suffering of the patient is the bulk of the tumour. Intralesional Laser ablation offers an alternative way to destroy the bulk of the tumor. The reduction in tumor volume allows good restitution of oral function and pain. There were 49 patients observed in this study. Many patients went into remission after laser ablation and Chemotherapy. The ensuing results were analyzed taking into account Quality and Quantity of life and the resulting Quality index was applied on the patients. Most patients had a good Quality Index post-procedure. All patients were highly satisfied with the procedure. There was an enhanced benefit noted in the quality of life and the expected overall survival time of the patients. Conclusion: Laser Ablation offers an alternative treatment in late-stage Oral Cancer for palliation as well as remission.
\end{abstract}

Keywords Oral Cancer, Laser Ablation, Late Stage Buccal Cancer, Quality Index

\section{Introduction}

Oral cancer is the most frequently occurring cancer in India in males. For all regions, the incidence of oral cancer for males and females was highest in the central region of India. For males, it was $64.8 \%$ and for females it was $37.2 \%$ at 70 years of age (1).

The aim in all studies so far in this category has been palliation (2). This is a multidisciplinary approach in which the main aim is to decrease pain and institution of feeding and maintenance of airway by any means. Some doctors also use surgery as a means of palliation (3) Various options include mandibulectomy with free and regional flaps. Quality of life parameters have been assessed in various options in management of Late stage Oral carcinoma (4).

Due to the specific anatomical sites and structures that characterize oral cancer, both the disease process and its treatment may greatly impair the body image and practical functions of patients in even the most essential life tasks such as breathing, speaking, swallowing, and eating. (5)(6). During the past six decades, both the mortality and 5-year survival rates among oral cancer patients basically remain unchanged. (7)(8) For these reasons, the improvement of quality of life after conventional surgery has gained the attention of the medical community.(9)

Preserving of Quality of life is of paramount importance in late stage oral cancer.

\section{Materials and Methods}

Thermoablation of tumours have been in use since 1990s. 
Several ablation techniques are currently available.

Thermoablation involves the following techniques

1. Radiofrequency

2. Microwave

3. Cryotherapy

4. Laser

All of these methods cause fatal damage at a cellular level and irreversible architectural deconstruction at a tissue level by thermal effects. Ablation of a tumour using one of these techniques, whether thermal or otherwise, requires applicators to be positioned from which the energy is delivered in situ. (10)

Lasers are currently approved by USFDA for treatment of soft issue tumours. (11) There has been a concerted effort to use ablative techniques in various cancers by institutions around the world with excellent results.(12) Increasingly laser treatment is being used in Oral and maxillofacial surgery in specialized institutions.(13)

Newer techniques with accurate sonographic and radiographic localisations have made this technique into a formidable field.

Though it is unlikely to replace conventional surgery .it is definitely emerging as an alternative in cases which are not willing for surgery or are not fit for surgery due to various reasons.

In many cases where the tumour is too big for resection, laser can be used for debulking of tumour for a better effect of the adjuvant therapy.

Laser Ablation is performed by using a laser and a medium which transports the laser light inside the tissue. The laser, which consists of a power source, a lasing medium, and reflecting mirrors, provides a monochromatic light (the light is emitted at a specific wavelength), whose wavelength defines the properties of the laser and the interaction with biological tissue. The medium is usually a small diameter $(0.2-0.8 \mathrm{~mm})$ flexible optical fibre that transports the laser light inside deep organs. Laser-tissue interaction can be described by three phenomena: scattering, reflection, and absorption. The light absorbed by tissue is converted into heat. Prolonged exposure of tumour cells at temperatures ranging from $45^{\circ} \mathrm{C}$ to $55^{\circ} \mathrm{C}$ or short exposure at temperature higher than $60^{\circ} \mathrm{C}$ causes irreversible cell damage.(14)

Laser works by causing an irreversible damage to the cells when there has been a delivery of heat through laser probes.

Accurate placement of probes determines the final outcome of the destruction of the tumour.

As such knowledge of adjuvant technologies like CT scan MRI and ultrasonography is a must for a good result.

Laser ablation of Head and neck cancers is now a part of NCCN guidelines and Cancer.org. (15)

Main Aims of Conventional Palliation in Late Stage Buccal Cancer:

1. Reduction of pain
2. Administration of nutrition by natural or artificial means

3. Maintenance of airway

4. Psychological management of patient.

The aim of tumor control is not possible so not addressed in the above directions.

Palliation in Laser technology assesses all of above with debulking of the tumor with no surgical intervention

\section{Patients and Methods}

Laser Diode machine was used in this study of $60 \mathrm{~W}$. This was of a standard make by Gigaa laser. All the patients were assessed for inoperability of standard surgical procedure. The patients had been advised chemotherapy and radiation with a palliative intent.

This study was carried out between January 2017 and July 2020. A written and informed consent was obtained from all patients.

The criteria for inoperability were a wide resection of Upper and Lower Jaw in the buccal region.

Table 1. Age wise distribution of Buccal cancer patients included in the study

\begin{tabular}{|c|c|c|c|c|c|}
\hline Group & $\begin{array}{c}\text { Surgical } \\
\text { status }\end{array}$ & $\begin{array}{c}\text { No of } \\
\text { patients }\end{array}$ & Male & Female & Normal life expectancy \\
\hline 1 & Resectable & 34 & 30 & 4 & 18 months \\
\hline 2 & Unresectable & 15 & 12 & 3 & 8 months \\
\hline
\end{tabular}

The ages of patients ranged from 25 yrs to 70 yrs with a mean of 41.3 yrs

Resectable meant $\mathrm{R} 0$ resection not possible.

Unresectable where only option was chemotherapy and radiotherapy with palliative intent.

All patients had their oral, tracheal functions intact. Exclusion criteria

1. Large fungating tumour

2. Involvement of maxillary orbital floor

3. Large multiple lymph nodes.

4. Comorbid condition leading to Anaesthetic non fitness.

5. Inability to take chemotherapy for any medical reason.

The procedure was carried out under General Anaesthesia by Nasotracheal intubation with a bronchoscope. The tumour was visualised under Ultrasonography control. The laser fibre of 400 microns was inserted with the help of 18 gauze needle and the tumour was laserised under direct vision. The lymph nodes were similarly seen in the sonography and laserised. The outer margin of the laserisation was the outer extent of the tumour. All lymph nodes seen on sonography were laserised. All patients were administered Chemotherapy in standard protocol for Cisplatin, Paclitel and 5-FU. There was no radiation used after the Ablation procedure. 
Pain relief was assessed as per Numerical rating scale (NRS) - the intensity of pain is measured by asking the patient to select a number from 0 to 10 that describes the intensity of his pain: " 0 " means "no pain" and " 10 " means "unbearable pain.(16)

\section{Results}

Table 2. Pain relief as Assessed by NRS

\begin{tabular}{|c|c|c|}
\hline Patients & Pain relief & Percentage \\
\hline 41 & 2 & 83 \\
\hline 6 & 3 & 12 \\
\hline 2 & 4 & 4 \\
\hline
\end{tabular}

All patients had a $95 \%$ and above dissolution of the tumour in a single session by laser. This was a visual impression based on the necrotic white nature of the dead tumor.

$83 \%$ of patients had a excellent relief from pain within $48 \mathrm{hrs}$ of laser.12\% had a good relief and $4 \%$ had a satisfactory relief.

Table 3. Patients return to work assessed on percentage basis

Return to work $\mathrm{N}=49$

\begin{tabular}{|c|c|}
\hline Return to work & Percentage \\
\hline 35 & 70 \\
\hline 14 & 12 \\
\hline
\end{tabular}

$70 \%$ of cases patients were able to return to work and rest could continue with their daily activities at work.

Table 4. Recurrence in patients assessed by visual and scan reports in resectable patients

\begin{tabular}{|c|c|}
\multicolumn{1}{|c|}{ Recurrence Group 1 } & N=34 \\
\hline Nos & 6 \\
\hline 25 & 3 \\
\hline 7 & 2 \\
\hline 2 & Time in months \\
\hline
\end{tabular}

Table 5. Recurrence in patients assessed by visual and scan reports in Unresectable patients

Recurrence Group 2

$\mathrm{N}=15$

\begin{tabular}{|c|c|}
\hline Nos & Time in months \\
\hline 10 & 2 \\
\hline 4 & 4 \\
\hline
\end{tabular}

Patients of Group 1 of buccal cancer had a better result as far as recurrence was concerned

Group 1 patients had longer time for recurrence as compared to Group 2. (table 4 and 5). The recurrences were apparent after 6 months and within 2 months of stopping chemotherapy. Most recurrences were managed by re laserising the area every 3 weeks under local anesthesia. The procedure itself was done under OPD conditions and averaged 3 minutes.

The procedure was repeated on a monthly basis till the volume of recurrence and nodal recurrence exceeded the laser capabilities.

All patients were able to return to normal life within 2 weeks. The swelling decreased by more than $90 \%$ in 3 weeks. This was a visual confirmation based on pre procedure photographs.. 9 patients $(20 \%)$ of patients had bleeding in $2^{\text {nd }}$ week due to tumour detachment which was managed by local compression.

The average life span of all patients considered was 1 year with life span ranging from 8 months at the least and 4 years at the most. This was considerably better at expected life span of 3 months in this category. (17). The person at 4 years is still alive till date.

Table 6. Expected life expectancy v/s observed life expectancy after Laser Ablation

\begin{tabular}{|c|c|c|c|c|}
\hline Group & Surgical status & $\begin{array}{c}\text { No. of } \\
\text { patients }\end{array}$ & $\begin{array}{c}\text { Normal life } \\
\text { expectancy }\end{array}$ & $\begin{array}{c}\text { Post laser Average } \\
\text { life expectancy }\end{array}$ \\
\hline 1 & Resectable & 34 & 18 months & 24 months \\
\hline 2 & Unresectable & 15 & 8 months & 14 months \\
\hline
\end{tabular}

All patients had a remission with a near normal quality of life. The main complaints were formation of Oral fistula in buccal cancer patients whose tumors had touched the skin and marginally fungated out. Most of these fistulas closed within 6 weeks. Persistent oral fistulas were managed by plugging tightly with plastic dressing. Other side effect was in drawing of cheek due to resolution of tumour and fibrosis. (Figure 5 and 7) $90 \%$ of our patients fell in good category and $10 \%$ fell in satisfactory category

Case 1 , a 40 year old male patient presents with unresectable buccal cancer. (Figure 1), Intra oral Figure shows extensive involvement of buccal mucosa with involvement of upper and lower jaw (Figure 2). Post laser and chemotherapy after 6 months shows a swelling decreased of the face with no neck swelling (Figure 3), Intraoral Figure shows no evidence of tumour (Figure 4) use Fig. in place of Figure 


\section{Case 1: Unresectable buccal cancer}

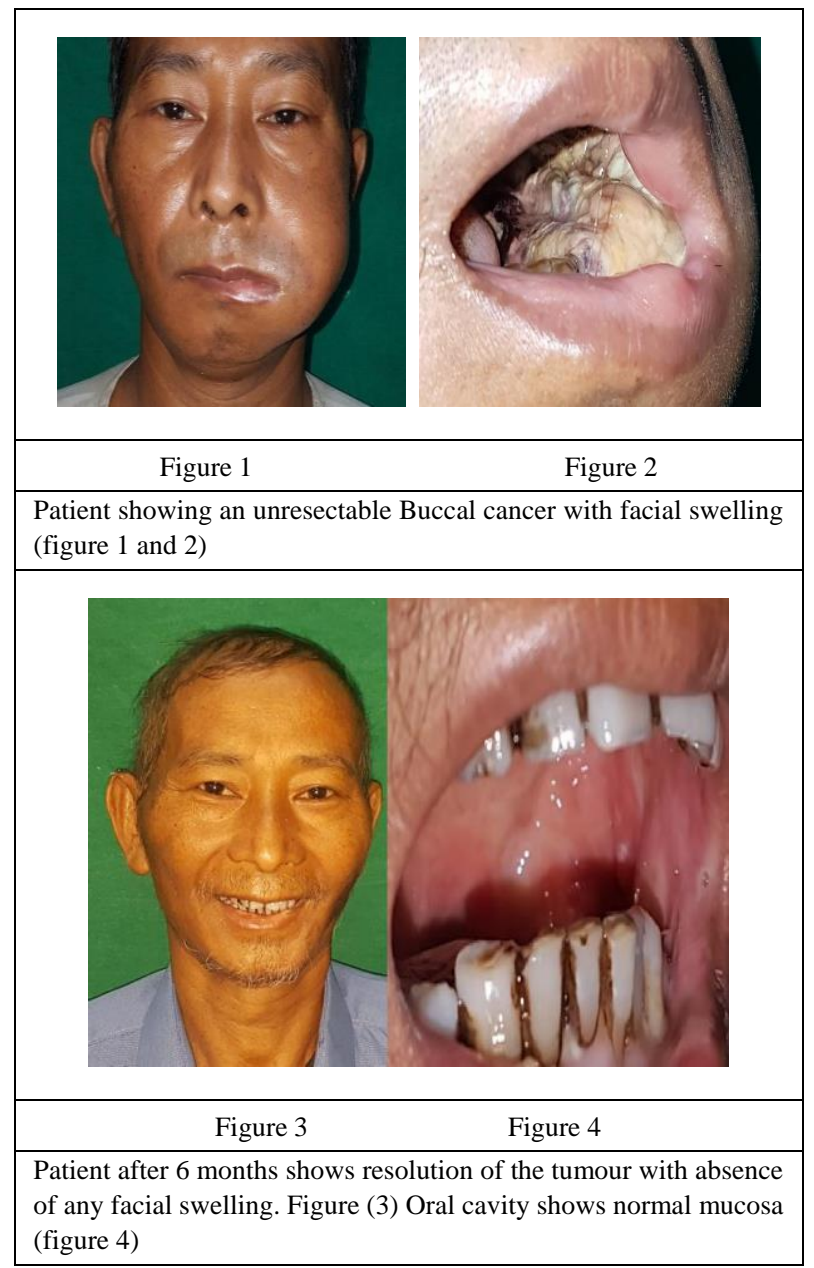

Case 2, a resectable Buccal Cancer, 65 year old male patient presents with fungating tumour with minimal skin involvement (Figure 5) and (Figure 6). Post laser and chemotherapy 1 year.

\section{Case 2: Resectable Buccal Cancer}

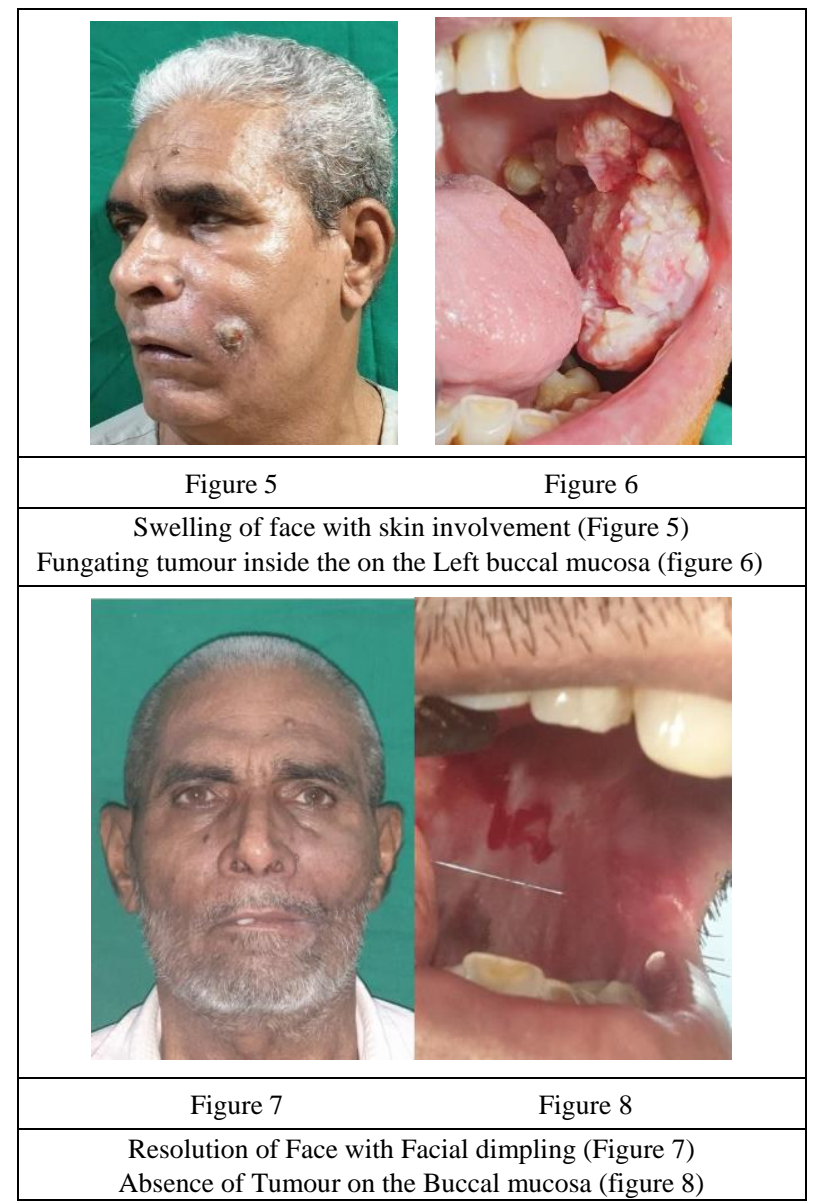

No cosmetic deformity, retraction of cheek on ipsilateral side. No recurrence and no evidence of tumour (Figure 7) and (Figure 8).

To better assess the effectiveness of surgical procedures in cases of Oral cancer we propose to analyze patients through a feature called Quality Index. It is a combination of Quality of life assessment with Quantity of Life.

Table 7. Most common Quality of Life parameters and points given to the observations

\begin{tabular}{|c|c|c|c|c|}
\hline \multicolumn{5}{|c|}{ Quality of Life Post Operatively of Oral cancer patients } \\
\hline Sr no & Feature & 1 & 2 & 3 \\
\hline 1 & Cosmesis & Confined to home & $\begin{array}{c}\text { Confined to family and } \\
\text { friends }\end{array}$ & $\begin{array}{c}\text { Able to interact } \\
\text { With office colleagues }\end{array}$ \\
\hline 2 & Diet & Tube feeding & Liquids & Full diet \\
\hline 3 & Speech & Hand gestures & Family & $\begin{array}{c}\text { Comprehendible by } \\
\text { everyone }\end{array}$ \\
\hline 4 & Pain & Pain killers all day & Once a day & No pain killers \\
\hline 5 & $\begin{array}{l}\begin{array}{l}\text { Drooling from } \\
\text { mouth }\end{array} \\
\end{array}$ & All day & Intermittent & None \\
\hline 6 & Sleep & Sedatives & Intermittent & Full sleep \\
\hline 7 & Weight & $\begin{array}{l}\text { Loss by more than } \\
10 \% \text { of pre surgery }\end{array}$ & Same as pre surgery & Weight gain \\
\hline
\end{tabular}


Table 8. Patient numbers as assessed by Quality of Life

Nos=patient Nos

\begin{tabular}{|c|c|c|c|c|c|c|c|}
\hline Sr no & Feature & $\mathbf{1}$ & Nos & $\mathbf{2}$ & Nos & $\mathbf{3}$ \\
\hline 1 & Cosmesis & $\begin{array}{c}\text { Confined to } \\
\text { home }\end{array}$ & 0 & $\begin{array}{c}\text { Confined to } \\
\text { family and } \\
\text { friends }\end{array}$ & 2 & $\begin{array}{c}\text { Able to interact } \\
\text { With office colleagues }\end{array}$ \\
\hline 2 & Diet & Tube feeding & 0 & Liquids & 0 & Full diet \\
\hline 3 & Speech & Hand gestures & 0 & Family & 0 & Comprehendible by everyone \\
\hline 4 & Pain & $\begin{array}{c}\text { Pain killers all } \\
\text { day }\end{array}$ & 0 & Once a day & 4 & No pain killers \\
\hline 5 & $\begin{array}{c}\text { Drooling from } \\
\text { mouth }\end{array}$ & $\begin{array}{c}\text { All day } \\
\text { Sleep }\end{array}$ & $\begin{array}{c}\text { Sedatives } \\
\text { (than }\end{array}$ & 0 & Intermittent & 0 & None \\
\hline 7 & Weight & $\begin{array}{c}\text { Los by more } \\
10 \% \text { of pre } \\
\text { surgery }\end{array}$ & 3 & $\begin{array}{c}\text { Same as } \\
\text { pre surgery }\end{array}$ & 25 & Full sleep \\
\hline
\end{tabular}

Table 9. Quantity of life and points given in increasing order of survival

\begin{tabular}{|c|c|c|c|c|}
\hline Time & $\mathbf{1}$ & $\mathbf{2}$ & $\mathbf{3}$ & $\mathbf{4}$ \\
\hline Months & 0 to 6 months & 6 to 18 months & $\begin{array}{c}18 \text { months to } 24 \\
\text { months }\end{array}$ & $\begin{array}{c}\text { More than 24 } \\
\text { months }\end{array}$ \\
\hline Nos & 0 & 25 & 20 & 4 \\
\hline
\end{tabular}

\section{Quality Index}

Quality of Life X Quantity of Life

Table 10. Patients studied on Quality Index in the study

\begin{tabular}{|c|c|c|}
\hline & Points & Nos \\
\hline Poor & $7-10$ & 0 \\
\hline Average & 10 to 14 & 0 \\
\hline Satisfactory & 15 to 40 & 32 \\
\hline Good & 41 to 84 & 17 \\
\hline
\end{tabular}

In our study using laser for ablation of Late stage Buccal Cancer (Table 10)

$65 \%$ patients had a satisfactory outcome

$35 \%$ patients had a good outcome

\section{Discussion}

Oral cancer as discussed earlier is a major health problem in India Wide consumption of Tobacco and Alcohol is attributed to this statistic in India. Dental problems in the form of sharp tooth or ill-fitting dentures are also causative factors in this cancer. Most patients present in India with stage 4 cancer also called inoperable or unresectable cancers due to late diagnosis and lack of primary health care in many areas.(18)

The treatment modalities differ on the stage and the location of the disease. The area's most commonly involved are buccal mucosa, retro molar trigone, tonsils and tongue. The buccal area includes alveolar area.
Inoperative cancers are divided into resectable where R0 status cannot be obtained and inoperable where no surgery can be attempted due to the size of the tumour. NACT-Neo Adjuvant Chemo therapy is attempted in these patients where the average response rate is $30 \%$ of tumour in $30 \%$ of patients.(17) with average survival time being 18 months after surgery following NACT. The average survival time in patients without surgery was 3 months and with surgery was 8 months in other studies (3). Most anteriorly based diseases have a surgical option and most posterior based diseases have chemotherapy and radiotherapy as treatment option. The treatment option of surgery is based on a wide three dimensional excision of the tumour accompanied by chemotherapy and radiotherapy.(5). Stage 4 cancer in Oral cancer refers to any cancer more than $4 \mathrm{cms}$ in any one dimension on a scan report or actual measuring. Stage 4 also refers to local extension of tumour to surrounding skin, muscle and bone. It also involves than 1 malignant node. (6).

The main limiting factor in assuring a long-term survival in cases of Late stage oral cancer is due the phenomenon known as field cancerization (19). Field cancerisation refers to the phenomenon of multiple origins of deposits of genetically altered cells in the oral mucosa which are more prone to turn malignant as time goes by. This phenomenon is more apparent in late stage cancers and in patients ingesting tobacco, Alcohol products.

This leads to an inevitable recurrence in the surrounding tissue spaces of a surgically corrected tumor bed with excision and a surgical Flap. This makes any surgery in late stage oral cancer mainly palliative even if carried out with a curative intent with adequate surgical margins.(19)(20). Several studies have emphasized the Limited Quality of Life obtained after mandibular/maxillary removal operations. Considering both the studies in comparison an argument can be made for laser being an alternate form of management since it can give a better quality of life considering the above parameters.(17)(21) 


\section{Conclusions}

Laser ablation surgery offers an excellent way to palliate patients starting with relief from pain, reduction of swelling and restitution of oral intake. Many of these patients can be stated to be in remission. There was a definite correlation between years of tobacco use and the frequency. Patients having more years and frequency fared worse than patients having less consumption of tobacco products. The quality of life is maintained to a large extent and the there is a substantial increase in the overall survival time. The results were satisfying for the 80 percent of the patients.

\section{Conflict of Interest}

The authors declare they have no conflict of interest in the above study.

\section{REFERENCES}

[1] https://ncdirindia.org/ncrp/ALL_NCRP_REPORTS/PBCR_ REPORT_2012_2014/ALL_CONTENT/Printed_Version.ht $\mathrm{m}$

[2] Min Nie, Chang Liu, Yi-Chen Pan, Chen-Xi Jiang, Bao-Ru $\mathrm{Li}$, Xi-Jie Yu, Xin-Yu Wu, and Shu-Ning Zheng. Development and evaluation of oral Cancer quality-of-life questionnaire (QOL-OC); BMC Cancer. 2018; 18: 523.

[3] R. Mroueh, A. Haapaniemi, T. Saarto, L. Grönholm, R. Grénman, T. Salo, and A. A. Mäkitie. Non - curative treatment of patients with oral tongue squamous-cell carcinoma. Eur Arch Otorhinolaryngol. 2019; 276(7): 2039 2045 .

[4] H Cocks, K Ah-See, M Capel, and P Taylor; Palliative and supportive care in head and neck cancer: United Kingdom National Multidisciplinary Guidelines. J Laryngol Otol. 2016 May; 130(Suppl 2): S198-S207

[5] Jatin P. Shah, Ziv Gil; Current concepts in management of oral cancer surgery. Oral Oncol. 2009 Apr-May; 45(0): 394 401

[6] https://www.cancer.org/cancer/oral-cavity-and-oropharynge al-cancer/detection-diagnosis- staging/staging.html

[7] National Cancer Institute. Oral cavity and pharynx Cancer $[\mathrm{EB} / \mathrm{OL}] 2013$
[8] World Health Organization. Fact sheet no. 297: cancer [DB/MT]. WHO Media Centre. 2014

[9] Li W, Xu Z, Liu F, Huang S, Dai W, Sun C. Vascularized free forearm flap versus free anterolateral thigh perforator flaps for reconstruction in patients with head and neck cancer: assessment of quality of life. Head Neck. 2013; 35: $1808-1813$

[10] Emiliano Schena, Paola Saccomandi and Yuman Fong, Bing $\mathrm{Xu}$. Laser Ablation for Cancer: Past, Present and Future. J Funct Biomater. 2017 Jun; 8(2): 19

[11] https://www.fda.gov/radiation-emitting-products/surgical-a nd-therapeutic-products/medical-lasers

[12] Deepak G, Jagannath P, Parikh V, Shah Rajiv. Radiofrequency ablation of liver tumors: experience with open and percutaneous approach. Indian Journal of Gastroenterology, 2006, Vol. 25, March-April

[13] Laser tumor treatment in oral and maxillofacial surgery. SAOT - School in Advanced Optical Technologies, University Erlangen-Nuremberg, Erlangen 91054, Germany. https://doi.org / 10.1016/ j.phpro.2010.08.125

[14] Izzo F. Other Thermal Ablation Techniques: Microwave and Interstitial Laser Ablation of Liver Tumors. Ann. Surg. Oncol. 2003; 10:491-497

[15] https://www.cancer.org/treatment/treatments-and-side-effect s/treatment-types/lasers-in-cancer- treatment.html

[16] Arūnas Ščiupokas, Liuda Brogienè and Dalia Skorupskienė March 2019 DOI: 10.5772/intechopen.84452

[17] Vidisha Tuljapurkar, Harsh Dhar, Aseem Mishra, Swagnik Chakraborti, Pankaj Chaturvedi, Prathamesh S Pai. The Indian scenario of head and neck oncology - Challenging the dogmas; South Asian Journal of Cancer; Vol 5 (3), 105-116

[18] Lohia Nishant, Bhatnagar Sharad, Singh Sankalp, Prashar Manoj, Subramananiam Anand, Viswanath Sundaram, Sahu P K, Rai Ajay. Survival trends in oral cavity cancer patients treated with surgery and adjuvant radiotherapy in a tertiary center of Northern India: Where do we stand compared to the developed world? SRM Journal of research in dental sciences, 2019, Vol.10, Issue 1, 26-31

[19] Slaughter DP, Southwick HW, Smejkal W. Field cancerization in oral stratified squamous epithelium; clinical implications of multicentric origin. Cancer. 1953 Sep; 6(5):963-8

[20] Meenakshi Mohan and Nithya Jagannathan. Oral Field Cancerization: An Update on Current Concepts. Oncol Rev. 2014 Mar 17; 8(1): 244

[21] Bundgaard T, Tandrup O, Elbrønd O. A functional evaluation of patients treated for oral cancer, a prospective study. Acta Otorhinolaryngol Ital. 2008 Jun; 28(3): 120-125. 